\title{
Drilling of Early Cretaceous Oceanic Anoxic Event 1a in Southern France
}

by Sascha Flögel, Wolfgang Kuhnt, and Michel Moullade

doi:10.2204/iodp.sd.9.03.2010

\section{Introduction}

The massive concentration of black, laminated, organic carbon-rich shales at certain time periods during the Cretaceous period ( 140-65 Ma) led to the concept of Oceanic Anoxic Events (OAEs). These events are characterized by unusually enhanced preservation of organic matter across environments ranging from the deep oceans to shelf seas. Enhanced productivity of siliceous and organic-walled primary producers and/or strongly dysaerobic or anoxic conditions in all major oceans were both suggested as likely causes (Meyer and Kump, 2008). Fundamental chemical and biological changes in the world ocean must have been associated with these events.

While the geographic extent of most black shale events in the Cretaceous is still under debate, the two main OAEs in the early Aptian (Selli Event: OAE1a, 119 Ma) and at the Cenomanian-Turonian boundary (Cenomanian/Turonian Boundary Event: OAE2, 94 Ma) have proven to be of global distribution (Grötsch et al., 1998). Estimates of organic matter accumulation rates and recent findings of biomarkers for cyanobacteria, a proxy for photic zone anoxia in organic-carbon rich sediments of both OAEs, indicate high levels of productivity as observed in extreme upwelling environments today (Meyer and Kump, 2008). Carbon-isotope studies demonstrate that both the Aptian and the Cenomanian-Turonian black shales are associated with a positive carbon-isotope excursion in marine pelagic and shallow-water carbonate, marine organic matter, and terrestrial higher-plant material. These positive carbon-isotope excursions thus offer a means of correlation between sediments deposited in the oceans and on the continents. The Aptian event is also associated with an initial negative carbon-isotope excursion, recently interpreted as due to dissociation of methane hydrates. It has been suggested that both phenomena, OAEs and methane-release events, were results of increased global temperatures caused by high $\mathrm{CO}_{2}$-levels in the atmosphere (Wagner et al., 2007). Massive sequestration of organic carbon during an OAE, however, would draw down $\mathrm{CO}_{2}$ and produce global cooling with respect to pre-OAE levels (Forster et al., 2007).

After decades of research, timing and causes of onset and spread of Cretaceous OAEs still remain a topic of vigorous debate. Deciphering the driving mechanisms and time scales for the onset and spread of OAE1a is the main objec- tive of this study. Due to the lack of complete, unweathered sections of the early Aptian, a well-studied type locality of early Aptian deposition in southern France was selected for coring.

\section{La Bédoule section and coring}

The drilling campaign took place during May 2009 at Roquefort-La Bédoule about $20 \mathrm{~km}$ southeast of Marseille. The drill sites are located in abandoned quarries in close proximity to outcrops with an existing stratigraphic framework (Figs. 1, 2). The target interval was successfully encountered below the weathering zone.

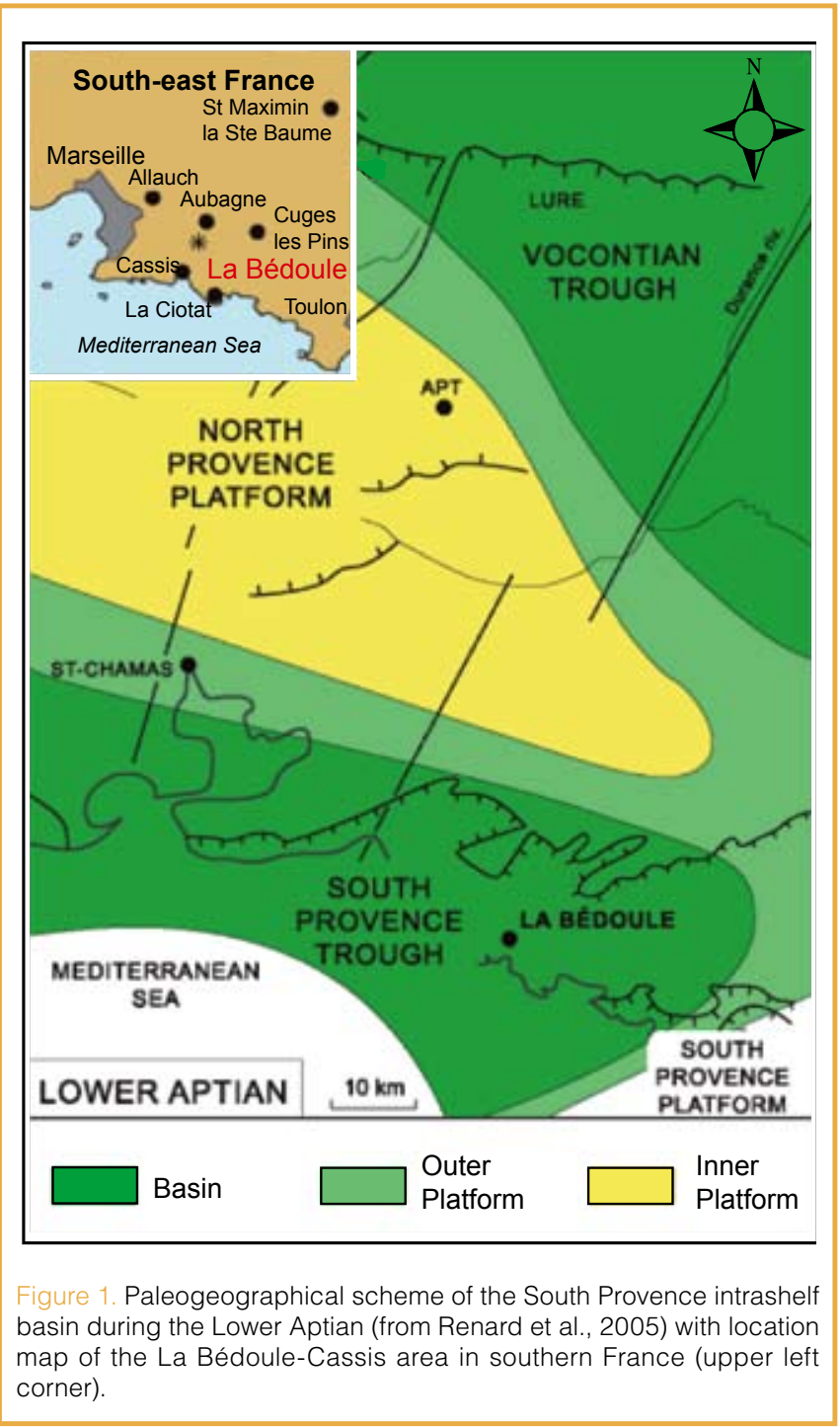




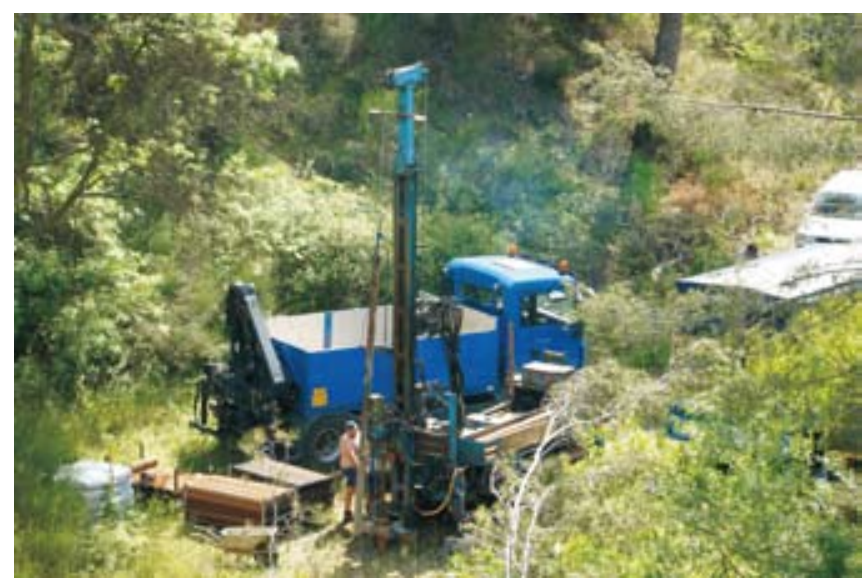

Figure 2. Drilling operations at section LB1 with a trailer-mounted rig.

The regional and palaeogeographic setting of the stratotype is that of an intrashelf basin-the South Provence Trough-that formed within the Urgonian Carbonate Platform during late Barremian times (Masse et al., 1993). It was isolated from the Vocontian Basin to the north by the North Provence Platform (Monts de Vaucluse - Mont Ventoux) and bounded to the southeast by the South Provence Platform (Mont Faron). Although quite restricted in extent initially, this trough extended westward during Lower Aptian times to join the North Pyrenean Basin of the

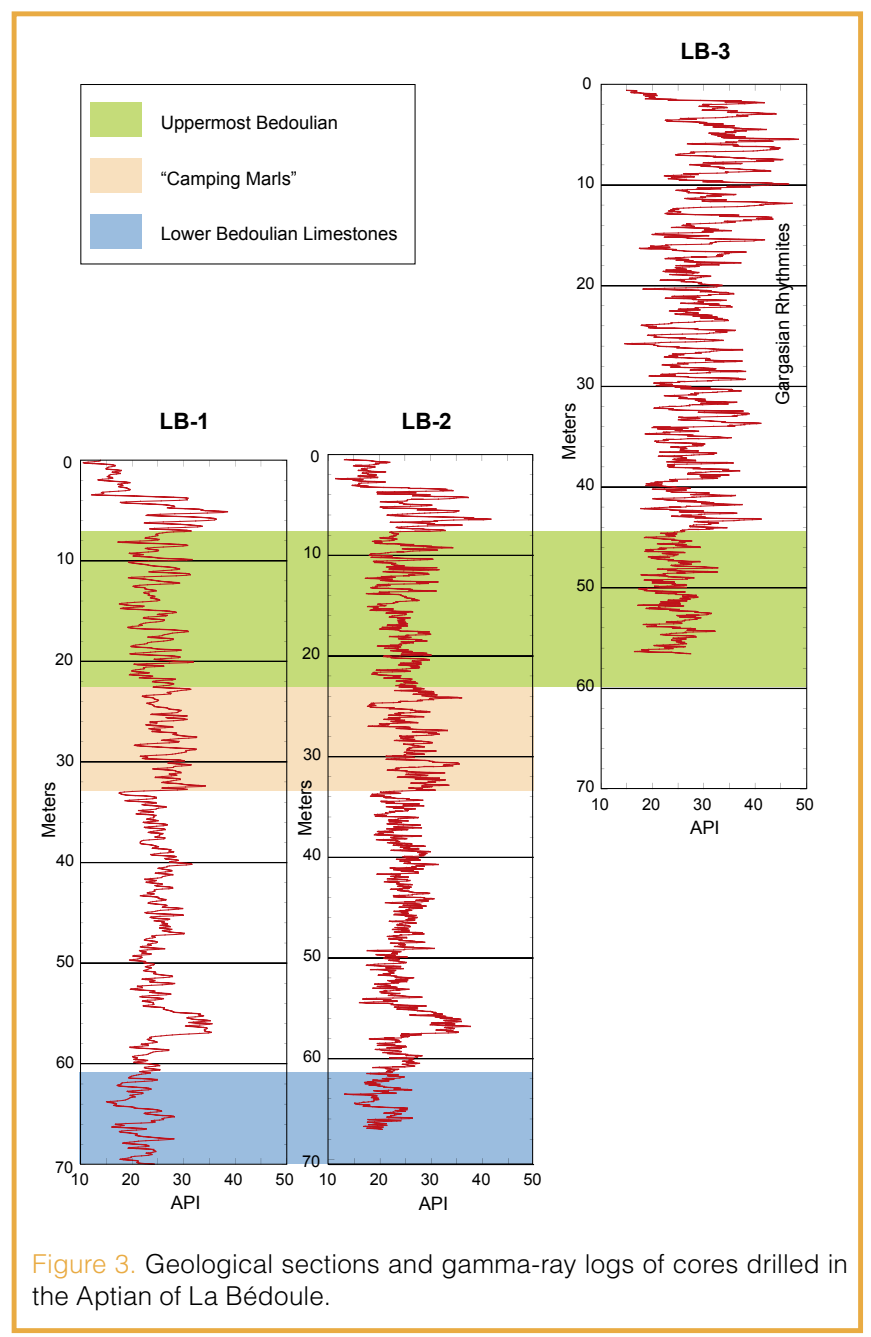

'Deshayesites Marls' (Masse et al., 1993). As described by Moullade et al. (1998a, 1998b) and Masse (1998), the section at La Bédoule presents three lithological members:

- Upper Barremian-lower Bedoulian limestone member overlying the Urgonian Platform deposits

- Upper Bedoulian alternating marls and limestones member

- Top Bedoulian - lower Gargasian marly member

The discrimination of these members is of practical value in the field but does not accurately reflect the $\mathrm{CaCO}_{3}$ content which always remains high (80-95\%; Masse, 1998). The position of the main OAE1a carbon isotope excursion within the "Camping Marls" in the Upper Bedoulian alternating marls and limestones member is correlated bed by bed to a nearby outcrop section at the former camping ground of $\mathrm{La}$ Bédoule (Fig. 3). Three cores at two different sites were drilled with a total recovery of more than 180 meters and a core diameter of $11 \mathrm{~cm}$. Of the three holes, two are covering lower Bedoulian limestones through uppermost Bedoulian sediments $(\mathrm{LB} 1=70 \mathrm{~m}$ and $\mathrm{LB} 2=67 \mathrm{~m})$, while LB3 $(56 \mathrm{~m})$ recovered uppermost Bedoulian through middle Gargasian strata. The cores were retrieved continuously with $100 \%$ recovery and minimal disturbance at core breaks, which can be bridged by the parallel core in all cases. Cores were cut into working and archive halves and are stored under cool conditions in the core repository at IFM-GEOMAR, Germany.

\section{Objectives}

The drilling campaign was initiated to recover high quality sediment cores in order to determine the timing, succession of events, and feedback mechanism at the onset of OAE1a. Goals include times series analysis of continuously measured proxy data (gamma rays, visible light spectrometry, and XRF scanning) to develop orbital chronologies and to determine leads/lags between different proxy data. Additionally, it is planned to develop ultra-high resolution isotopic $\left(\delta^{13} \mathrm{Ccarb}\right.$ and $\delta^{13} \mathrm{Corg}$ ) records of the periods immediately before and during the initial carbon isotope shifts in the early Aptian. These will include proxy records for marine organic carbon accumulation (TOC Rock-Eval records), deep water oxygenation (benthic foraminiferal dissolved oxygen index, redox-sensitive elements such as $\mathrm{Mn} / \mathrm{Fe}, \mathrm{U} / \mathrm{Mo}, \mathrm{Re} / \mathrm{Mo}$, and Te/Se, and isotope systems such as $\delta^{98 / 95} \mathrm{Mo}$ ), and SST ( $\delta^{18} \mathrm{O}$, TEX86, and Ca-isotopes) at intermediate resolution and/or at critical points of the high-resolution data series. A further aim will be determining the amplitude and phasing of $\mathrm{pCO}_{2}$ changes during the OAE as a crucial boundary condition for climate models by using boron isotopes (Pearson and Palmer, 2000).

Initial foraminiferal biostratigraphy indicated that the upper portion of LB2 top is still uppermost Bedoulian (Furcata zone) and that the top of LB3 can be attributed to 
the very basal Globigerinelloides barri zone (middle Gargasian). High-resolution wireline gamma-radiation of the cores was registered to serve for detailed cross-correlation of wells (Fig. 3).

High-resolution analyses of the core are currently underway, including foraminiferal and nannoplankton biostratigraphy (University of Marseille and University of Lyon), and visible light spectrophotometry, XRF scanning, and stable isotope geochemistry (University of Kiel). The advanced analytical phase of this multi-disciplinary project is scheduled for the next three years.

\section{Acknowledgements}

This study is an integral part of the SFB 754 Collaborative Research Center "Climate-Biogeochemistry Interactions in the Tropical Ocean" established by the Deutsche Forschungsgemeinschaft at the University of Kiel and IFM-GEOMAR. We thank Stölben GmbH, especially André Herrlich and Thomas Flohr, for their skills and patience during the drilling. The Ville of Roquefort-La Bédoule (Département des Bouches du Rhone) and the landowner of the main drilling site (Mme. Fiani) generously granted access and facilitated drilling in any possible way. We also want to especially acknowledge the help of Thomas Grelle and Thomas Wonik from the Leibniz Institute for Applied Geophysics in Hannover who kindly provided the wireline logging equipment and support.

\section{References}

Forster, A., Schouten, S., Moriya, K., Wilson, P.A., and Sinninghe Damsté, J.S., 2007. Tropical warming and intermittent cooling during the Cenomanian/Turonian oceanic anoxic event 2: sea surface temperature records from the equatorial Atlantic. Paleoceanography, 22:PA1219, doi:10.1029/ 2006PA001349.

Grötsch, J., Billing, I., and Vahrenkamp, V., 1998. Carbon-isotope stratigraphy in shallow-water carbonates: implications for Cretaceous black-shale deposition. Sedimentology, 45(4):623-634.

Masse, J.-P., 1998. Sédimentologie du stratotype historique de l'Aptien inférieur dans la région de Cassis-La Bédoule (SE France). Géologie Méditerranéenne, 25 (3-4):31-41.

Masse, J.-P., Bellion, Y., Benkhelil, J., Dercourt, J., Guiraud, R., and Ricou, L.E., 1993. Lower Aptian (114-112 Ma). In Dercourt, J., Ricou, L.E., and Vrielynck, B. (Eds.), Atlas Tethys Paleoenvironmental Maps. Explanatory Notes. Paris (Gauthier-Villars), 135-152.

Meyer, K.M., and Kump, L.R., 2008. Oceanic euxinia in Earth history: causes and consequences. Ann. Rev. Earth Planet. Sci., 36:251-88.

Moullade, M., Kuhnt, W., Bergen, J.A., Masse, J.-P., and Tronchetti, G., 1998a. Correlation of biostratigraphic and stable isotope events in the Aptian historical stratotype of La Bédoule (SE France). Comptes Rendus de l'Académie des Sciences - Series IIA - Earth Planet. Sci., 327:693-698.
Moullade, M., Tronchetti, G., Busnardo, R., and Masse, J.-P., 1998b. Description lithologique des coupes types du stratotype historique de l'Aptien inférieur dans la région de Cassis-La Bédoule (SE France). Géologie Méditerranéenne, 25(3-4):15-29.

Pearson, P.N., and Palmer, M.R., 2000. Atmospheric carbon dioxide concentrations over the past 60 million years. Nature, 406:695-699.

Renard, M., de Rafélis, M., Emmanuel, L., Moullade, M., Masse, J.-P., Kuhnt, W., Bergen, J., and Tronchetti, G., 2005. Early Aptian $813 \mathrm{C}$ and manganese anomalies from the historical Cassis-La Bédoule stratotype sections (S.E. France): relationship with a methane hydrate dissociation event and stratigraphic implications. Carnets de Géologie/Notebook on Geology, 2005/04 (CG2005_A04):1-18.

Wagner, T., Wallmann, K., Stüsser, I., Herrle, J.O., and Hofmann, P., 2007. Consequences of moderate 25,000 yr lasting emission of light $\mathrm{CO}_{2}$ into the mid-Cretaceous ocean. Earth Planet. Sci. Lett., 259:200-211, doi: 10.1016/j.epsl.2007.04.045.

\section{Authors}

Sascha Flögel, IFM-GEOMAR, Leibniz-Institut für Meereswissenschaften (an der Universität Kiel), Dienstgebäude Ostufer; 8C-110, Wischhofstr. 1-3, 24148 Kiel, Germany, e-mail: sfloegel@ifm-geomar.de.

Wolfgang Kuhnt, Christian-Albrechts-Universität zu Kiel (CAU), Institute of Geosciences, Marine Micropaleontology, Ludewig-Meyn-Str. 14, D-24118 Kiel, Germany, e-mail: wk@ gpi.uni-kiel.de.

Michel Moullade, Centre de Recherches Micropaléontologiques, Museum d'Histoire Naturelle, $60 \mathrm{Bd}$ Risso, 06000 Nice, France \& EA 4234 Laboratoire de Géologie des Systèmes et des Réservoirs Carbonatés, Université de Provence (Aix-Marseille I), Campus St Charles, Case 67, 3 Pl. Victor Hugo, 13331 Marseille Cedex 03, France

\section{Photo Credit}

Fig. 2: S. Flögel 